Carlos SMANIOTTO COSTA

Ina ŠUKLJE ERJAVEC

Juliane MATHEY

\section{Green spaces - a key resources for urban sustainability The GreenKeys approach for developing green spaces}

\section{Introduction}

Throughout the world cities are experiencing rapid change as a result of a strong process of urbanisation. The landscape which surrounds most of our cities is being converted to development at a still accelerating rate and with a high percentage of sealed-off ground. The urbanisation process is, in Europe, accompanied by a needed adjustment of economic, demographic and political situation (e.g. population decline, ageing, deindustrialisation, etc.). This rapid change has significant implications for the natural and urban environment, infrastructure requirements and the social composition of the urban society.

Following the principles of sustainable development, we all should be committed to that kind of development that meets the needs of the present, without compromising the ability of future generations to meet their own needs. It is no wonder that almost all urban development programmes set down ideas and ideals to develop our cities in a more longlasting way, especially concerning the environment and the social dimension. These programmes result from a process of searching for and then offering a better quality of life.

Offering quality of life in urban areas improving the quality of the environment remains indispensably. Urban green spaces are crucial elements of all cities. They affect the townscape, provide ecological diversity, have relevance for healthy citizens and societal well-being, deliver important economic benefits and form essential structural and functional spaces that make cities more liveable places (URGE-Team, 2004). Green spaces assume a key role in the efforts towards enhancing the urban environment and improving the quality of urban life and play a key role for performing sustainable ideals.

Frequent deficits in quantity and quality require appropriate strategies for the development and improvement of urban green systems. If we want to have an urban environment with fewer problems and as a better quality and good legacy for the future generations, we have to handle the situation and create the legacy now. This give rise to a number of questions:

- How can we adequately prepare our cities to be successful in the $21^{\text {st }}$ Century?

- What experiences will future generations gain from the urban environment?

- What roles will urban green spaces play in it?

\section{The Rationale of green spaces}

In GreenKeys an urban green space is defined as a public open space in an urban area which is predominantly characterised by a high percentage of vegetation and non paved surfaces. An urban green space is directly used for active or passive recreation; or indirectly used by virtue of its positive influence on the urban environment, serving the diverse needs of citizens and thus offering a good quality of life in cities. It can assume different characteristics, e.g. parks, gardens, squares, cemeteries and allotment gardens as well as woodlands and areas for nature and landscape conservation. Urban green is the sum of all green spaces combined to make up the urban green fabric or system.

Green spaces are acknowledged for making valuable environmental, social and people's well-being based contributions to the urban environment. The roles and benefits of green spaces are extensive and multifunctional. Several authors to a greater or lesser extent researched and delivered different evidences of the roles and benefits ${ }^{[1]}$. This extensibility and multifunctionality mean that a green space can bring different benefits in different ways, to different users and with different results. Urban green spaces play an important role in relation to the quality of neighbourhoods and are notable in contributing to the delivery of community identity, as they shape the character and the image of a city.

Recognising the values green spaces can assume und the benefits they can provide do not, however, mean that green space development enjoys a high position in the political agenda. The low political position can have a manifold of reasons - in light of the GreenKeys experiences following can be mentioned:

- Urban green spaces are subject of natural processes, relations and interactions. These require long timescales for establishing the highest quality and therefore to make visible changes and benefits.

- Due to the direct benefits most cities and their inhabitants can already become satisfied with the simple existence of green spaces without questioning their qualities. Very often green spaces have very poor design innovation, obsolete equipments, bad accessibility, low ecological value, etc. More attention should be paid on increasing the quality - the better quality the more people will cherish the space.

- When a green space is run-down, offering low quality (e.g. poor ecological value) it is unlikely to have to be closed. In contrast, a dilapidated museum or swimming pool might have to be closed for health and safety reasons, potentially causing a local outcry.

- The urban green developing process are vulnerable to tangential conditions: no direct financial interest of investors and developers, growing cities face strong pressures for building sites while shrinking cities are confronted with decreasing tax revenues and an increasing incidence of spaces without use.

- Green spaces are seen as a factor of costs, especially regarding the maintenance requirements. The economic benefits that they can bring about are often not recognised and therefore not considered. 


\section{Increasing challenges for urban green space development}

Most cities have some form of planning instrument to influence the green space quantity and quality. In many cases, however, suitable overall concepts and strategies are missing, which combine the development and management of urban green spaces with general policies for urban development. The frequent deficits in quantity and quality all over Europe and the low value ascertained require appropriate management strategies for developing and improving urban green systems (URGE-Team, 2004). To secure the green space development in the era of sustainable development still requires dedicated hard work and, especially, personal engagement.

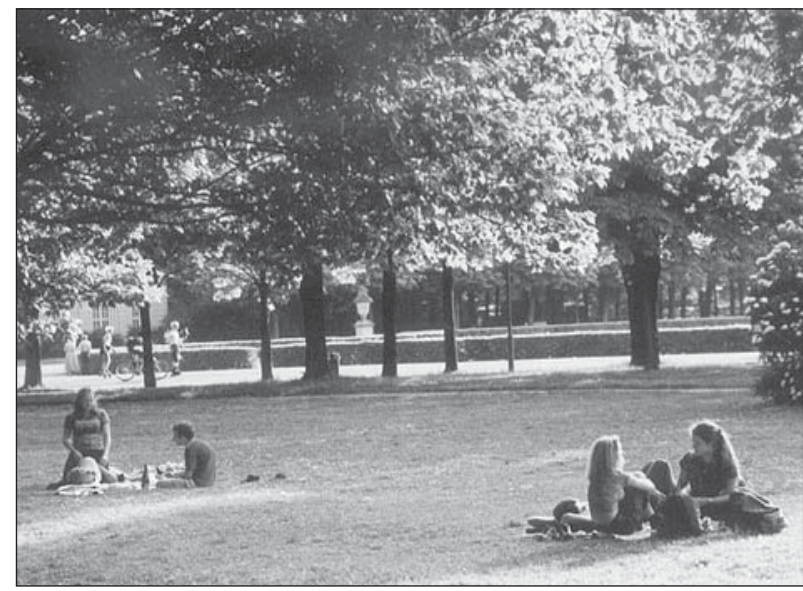

Figure 1: The Blüherpark in Dresden: Quality green spaces can also contribute to a sense of community identity and ownership (source: Scherzer, 2006).

If we are unable to demonstrate effectively the value to the environment and society that green spaces deliver we risk green spaces remaining on the periphery of public policy priorities and unable to attract more resources (URGE Team, 2004). To revert this calls for the formulation and adaptation of strategies to better place urban green space in the decision making process.

There is a need to face up to the current and future challenges of climate change, security and sustainable development. The European economy must become a model for sustainable development in the $21^{\text {st }}$ Century and urban green has to be seen as a contributor to the local economy. Outdoor activities, nature conservation and issues which are critical to amenity and the natural environment have to be encouraged.

\section{Shaping climate change}

In the last few years knowledge about climate change and its consequences has progressed substantially, confirming the belief that the warming of the Earth's climate is very likely to be due to human activities, especially through greenhouse gas emissions. In the discussion on the adjustment of cities to the negative consequences of climate change and the 'overheating' of urban areas, a good green space structure represents a good chance to re-arrange urban spaces and city outskirts to make them fit for the future.

Global climate change is a multi-sectoral overlapping challenge, with implication in economics, society, ecology and environment, scientific spheres that concern all cities. There is an urgent call upon the development of strategies and approaches to mitigate and to adapt to the effects of the climate change. Shaping urban structures to the effects of climate change is a lengthy process. Here there is also the need to network all relevant stakeholders in order to create a long-lasting strategy.

\section{Promotion of public health}

There is a relationship between access and quality of urban green space with population physical activities. The physical health, psychological and social development, the sense of well-being and quality of life are enhanced in general by spending time outdoor (de Vries, 2001).

Green spaces not only provide a habitat for plants and animals but also function as places of recreation and counteract urban stressors - noise, stench, heat and air pollution. Being outdoor further the process of recovery after illnesses and serve a "buffer function" in an era marked by rapid technological and social development and urbanisation. Green spaces also alleviate such causes of strain as crowded environments, time pressure and the loss of direction in life. Current sedentary lifestyles are encouraging people to become overweight. The obesity of the population can be also tackled through the provision of more adequate outdoor places for active sports and personal fitness. Parks are ideal places to take healthy exercise but an overweight person will not be attracted unless the park quality is high (Barber, 2005).

For this reason, green spaces constitute an important resource for designing and planning a healthy built environment. The quality of the urban environment depends very much upon the quality of the green spaces. In order to tackle the increasing problems green spaces have to be of a high quality of design and equipment, be safe and be readily accessible.

\section{GreenKeys - tackling of green space challenges as a common effort}

Tackling of green space development problems and challenges as a common effort is a goal set by the GreenKeys Project. The name given to the project reveals also its programme: Urban Green as a Key for Sustainable Cities. GreenKeys aims to create and implement concepts and strategies for sustainable urban development, based on urban green spaces that are adequate from the social, ecological and economic perspectives.

The project's three main objectives are:

1. To provide incentives for structural changes in cities by offering opportunities to improve green spaces through the implementation of pilot projects, and learn from the experiences gained; 
2. To develop a methodology with supportive tools to formulate an urban green space strategy to fulfil the demands concerning future needs; and

3. To use existing synergies to promote the transfer of knowledge through a network, by fostering the exchange of trans-national experiences.

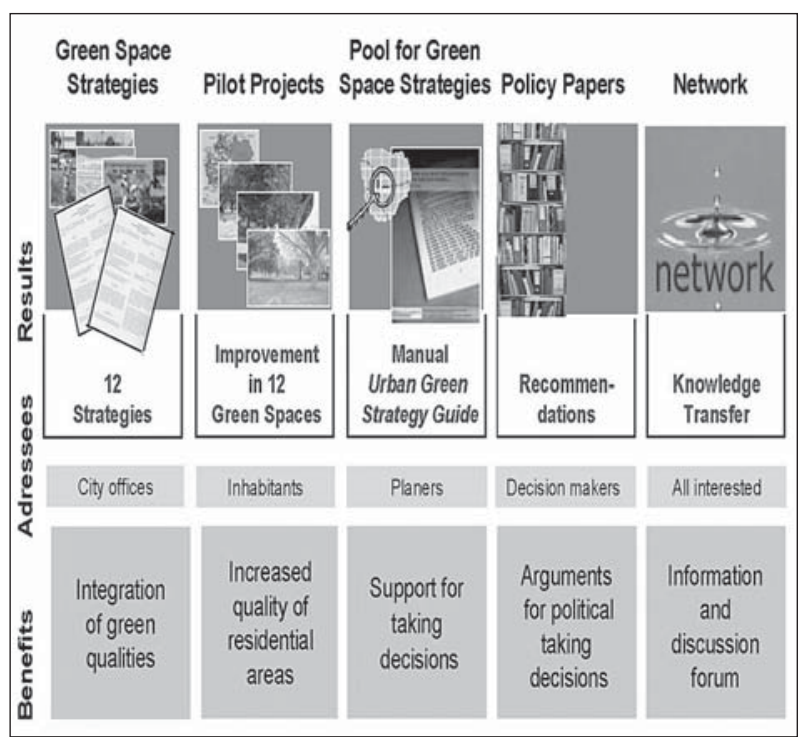

Figure 2: Project goals, structure, addressees and their benefits from Greenkeys (source: IOER, 2005).

To achieve these main objectives GreenKeys strove for five project outcomes and products (summed up in Figure 2):

1. Propose a general conceptual framework for formulating and adopting an Urban Green Spaces Strategy and develop supportive tools to help the implementation of this task. In the Chapter 7 the process of formulating an urban green space strategy in the partner cities is discussed and illustrated with some lessons learned.

2. Apply new ideas and approaches in the implementation of Pilot Projects to create new or improve existing green areas. Especially the active involvement of communities in the pilot project development was put forward, as an attempt to provide opportunities for community capacity building and empowerment.

3. Scrutiny the experiences gained and compile the results for a wider use into a Manual denominated GreenKeys @ Your City - A Guide for Urban Green Quality. This Manual created to function as a 'planning assistant' for green issues by delivering scientific and technical knowledge, is intended also to act as a 'Tool for Talking' - as a channel to advance and strengthen communication via guiding and prompting encourage the start of the (re)thinking and learning about the complex interactions between the needs of citizens, environmental requirements and the supply of green spaces.

4. Based on the premise that urban green spaces could be better managed if there were support from the national bodies and the European Union and backed by the analysed experiences GreenKeys formulated recommendations for city administrations, national states and the European Commission, in form of Policy Papers. Then the current European and some national urban policy documents show that the 'urban sustainability' subject has at least made it onto the political agenda - this, though, applies only indirectly for green space development. Explicit urban policies targeting green spaces at the national or European levels are non-existent. The GreenKeys recommendations were widely discussed with the project partners and with the participants of the closing conference, with took place in April 2008 in Sofia (BG). The recommendations are part of the Manual GreenKeys @ Your City - A Guide for Urban Green Quality.

5. The advancement of Urban Greening Strategies is a learning process that has to be encouraged by the exchange of knowledge and by comparing experiences. This called upon the creation of a Network to facilitate the transfer of knowledge. The tasks involved the analysis and dissemination of experiences, practical tools techniques needed by local practitioners to create and deploy cost-effective and sustainable urban strategies.

To increase the exchange and knowledge transfer GreenKeys organised as a closing event an international conference titled 'Urban Green Spaces - a Key for Sustainable Cities'. This conference took place in Sofia on $17^{\text {th }} / 18^{\text {th }}$ April 2008, and counted on around 170 attendees. In the Conference the interim results of the GreenKeys Project had been presented and discussed, the tools explained and the pilot projects and Urban Green Space Strategies of the partner cities demonstrated. The experiences from projects all over Europe had been collected and collated in a Conference Reader which is available for downloading at http://www.greenkeys-project. net/en/conference.html

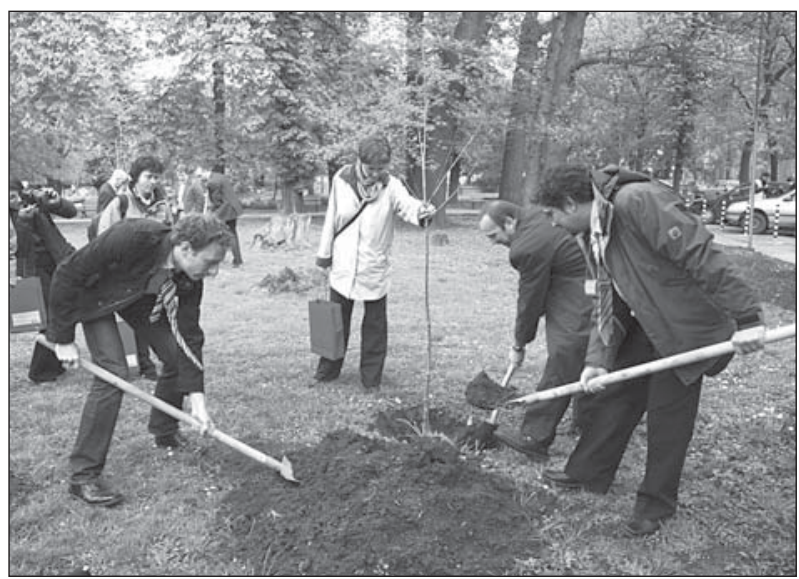

Figure 3: In the conference the delegates had the opportunity to participate in guided visits to Sofia's green spaces as well as to plant threes in a park, as a sign for the trust in the future.

\section{The GreenKeys Project and the project partners}

The GreenKeys Project was established to address the growing demands of providing healthy living conditions in urban areas. This work has involved 20 partner institutions: twelve cities and eight supporting institutions from Bulgaria, Germany, Greece, Hungary, Italy, Poland and Slovenia which worked together as an interdisciplinary team from May 


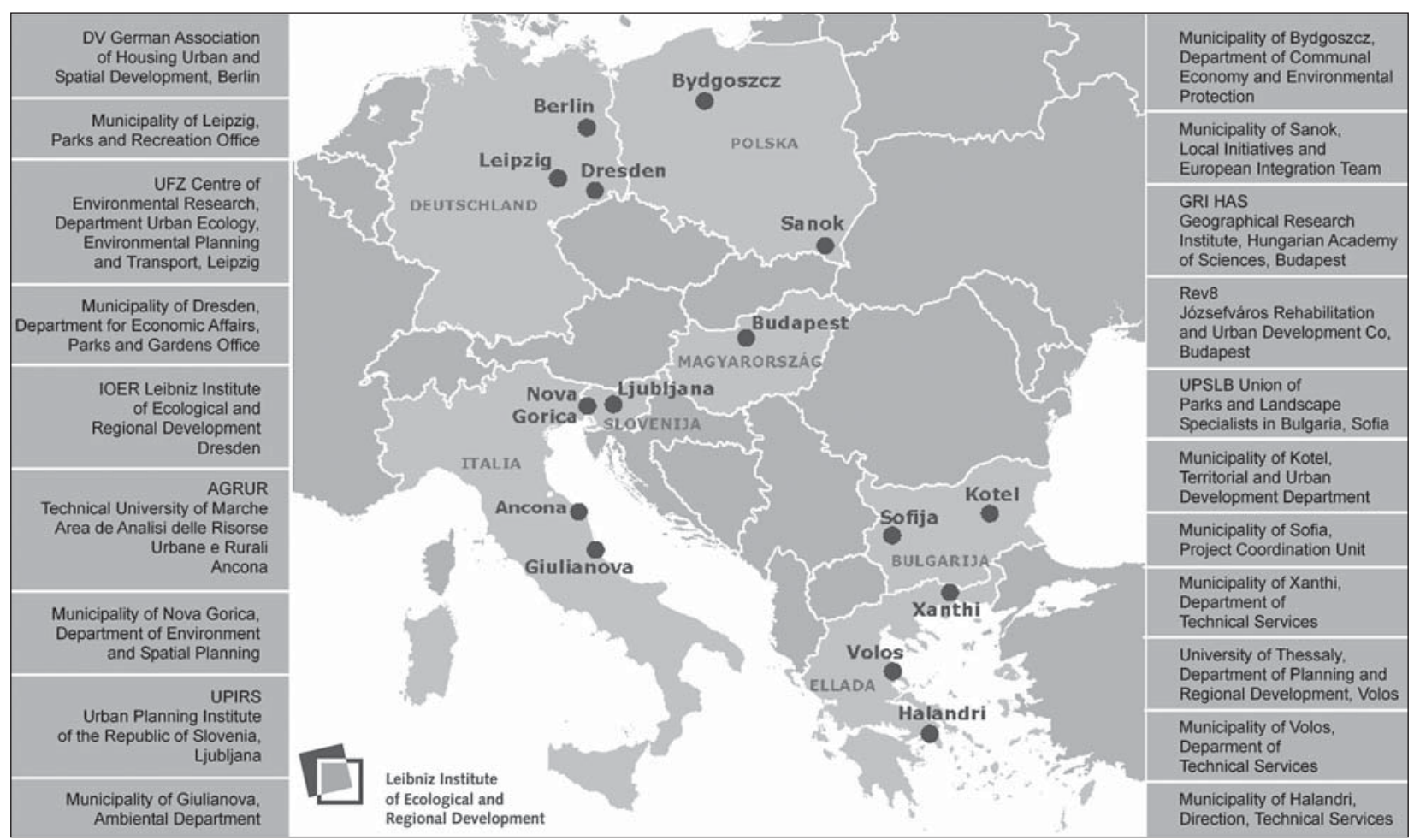

Figure 4: Map with an overview on all GreenKeys project partners (source: IOER, 2008).

2005 to August 2008.The Figure 4 provides an overview on all the GreenKeys partners. When the names of the cities are used here they refer to the department or departments that actively participated in the project. A detailed list of all partner institutions and participants with their contact data is available at the projects website.

GreenKeys is part-financed by the European Community Initiative INTERREG III B in the CADSES area and supported by the German Federal Ministry of Transport, Building and Urban Affairs. The leadership of the GreenKeys Project was fulfilled by the Office of Urban Green and Waste Management of the Municipality of Dresden, and the scientific coordination by the Leibniz Institute for Ecological and Regional Development.

The European dimension found a role within the project. The characteristics of the GreenKeys partner cities are so diverse that we could benefit from the good practices established. The cities differ in size, locations and functions. There were national capitals like Budapest or Sofia, regional capitals as Dresden (Germany) or Bydgoszcz (Poland) and small cities like Giulianova (Italy) or Kotel (Bulgaria).

\section{Challenges for an urban green space strategy}

As already mentioned above, one of the main objectives of the GreenKeys project was to develop a methodology, with supportive tools, to formulate an Urban Green Space Strategy. Through the dissemination or 'rolling out' of this methodology there is a wish to help cities throughout Europe to deal better and more successfully with this important aspect of the urban fabric. It is believed that this will help to improve the quality of life in the city and its sustainable development.

Green spaces exist in a great variety of shapes, structures and types within the city or urban fabric. The successful protection, creation, and development of the spaces are one of the key elements required to achieve sustainable urban development. The study and development of green spaces is, though, a complex subject, due to:

- the incidence of long-term natural processes that are involved in the growth and maturation of the living elements; and

- the fact that they represent public values and have an important role to play for the well-being and health of the inhabitants.

Their public acceptance and appreciation depends on the characteristics they possess, like appropriate provision, quality and accessibility.

The current trends that have been observed in many European cities suggest an increasing degradation in the general quality of existing urban green spaces. Without sufficient political and financial support from national or local authorities, other funding agencies or private investors, green space management is not likely to be able to reverse that process. The activities of public administrations, as responsible organisations tasked with securing and developing green spaces require a strategic approach for their development, planning and management.

A strategy is in general a policy for achieving a number of specific objectives. It should embrace the development of a major approach or method, which is suitable for attaining goals and resolving specific issues. In the case of green spaces, 
strategies are required to address a variety of (ecological) environmental, social and economic policies and sustainable development objectives. They must also be able to effectively defend the objectives against other issues of urban development and planning in the political discourse of decision-making and resource allocation.

The purposes of green space strategy are, therefore:

- to safeguard the future of green spaces;

- to improve the quality of urban areas and especially the neighbourhoods;

- to make urban areas more attractive and thereby attract more resources;

- to enhance the well-being of local people and tourists.

It follows that the strategy should lead towards the better use of green space potentials and help resolve conflicts in advance.

In GreenKeys we adopt the following understanding about urban green space strategy, which is based on CABE Space (2004): Urban green space strategy sets out a collective vision for improved green spaces, which meet community needs and provides a reference point for allocating resources and plans of action.

Cities differ, one from the other, each having individual and specific situations regarding spatial conditions, potentials, opportunities, problems and requirements, social, cultural and historical circumstances. Each differs in its city administrative organization, financial and personal resources and planning legislation. From the experiences of the GreenKeys city partners and other everyday practices we know that it is not possible, useful or effective to develop the same kind of strategy in the same way for each city. The starting point for the strategy development may, for example, require very different steps to be taken in different situations. In light of this it is to be expected that every city will have to find its own individual way for proceeding with the work.

But on the other hand, some general tasks and the following of certain steps and strategy content/structure in the process are mandatory and necessary for all cases in order to develop a green space strategy that will be effective and usable.

In recognition of these common strategic needs the GreenKeys project team decided to develop, together with the partner cities, a strategy building process that will be open and flexible enough to encompass different city situations but also supportive enough to make the development of green space strategy "simple and possible for all!" For achieving that we choose a dual approach for developing a methodology to set up and implement an Urban Green Spaces Strategy. This involved: the scientific partners, based on their own experiences; and analyses of literature and case studies. This led to the production of a set of tools for helping the cities with starting he strategy process, analyzing the city situation and for the formulation of an Urban Green Spaces Strategy

The partner cities, supported by the tools, started the process of formulating their own Urban Green Spaces Strategies and giving a feedback to scientific partners about the problems and obstacles they are facing, and about the usefulness of the tools they are using.

The GreenKeys Team analysed all the information from the cities, the legal and planning frameworks, wherein partner cities have to operate, as well as the strategy development process and developed the tools further for the final results. This gave rise also to the development of a Pool for Strategies that is an important part of the GreenKeys Manual that aims at helping cities outside the project to identify their green space potentials and to develop their own Urban Green Space Strategies.

With the "Pool for Strategies" the GreenKeys project intends to introduce and deliver new thinking and ideas that support the challenges of developing, formulating and implementing a green space strategy. The idea is based on the recognition that many cities have no experience or legal support for preparing a green space strategy and consequently face serious problems and obstacles to overcome from the very beginning of the process.

In analysing the experiences of the GreenKeys partner cities, as well as some other cases followed during the project, we found that there are several very common problems and unpredictable or unexpected situations that cities share in their everyday work. Most of these situations stand apart from and are not addressed in theoretical literature or guidebook instructions. For helping in these cases, in the "Pool for Strategies are collected different practical solutions with sometimes quite inventive procedures different cities has used to solve problems and obstacles of urban green space strategy building process. The GreenKeys project experience is that the examples of the possible ways to develop some important topics can be a good support or inspiration for other cities.

In the GreenKeys project we find out that, the most often problems and obstacles the cities may be confronted with in the starting part of the strategy building process are

- No or very low political or public support

- Strategy group building

- No spatial legislation support

- Defining starting points (developing visions),

- Defining aims and general priorities

Most of the cities in the GreenKeys project succeeded to find a way to overcome these problems and obstacles and start with a strategy building process.

For the Analytical part of the strategy building process the most common problems are lack of good and useful data and financial (and human) resources to support this part of the process. So the different possible examples of analytical approaches were collected and some analytical tools (presented in the next chapter) were developed to help cities to organize that part in a best effective and useful way.

Special focus was put on the issues of the analytical summary and urban green space typology building and setting local standards that can provide a good basis for the further development of the strategy, especially for preparing the strategic issues, the priorities and the action plan. 


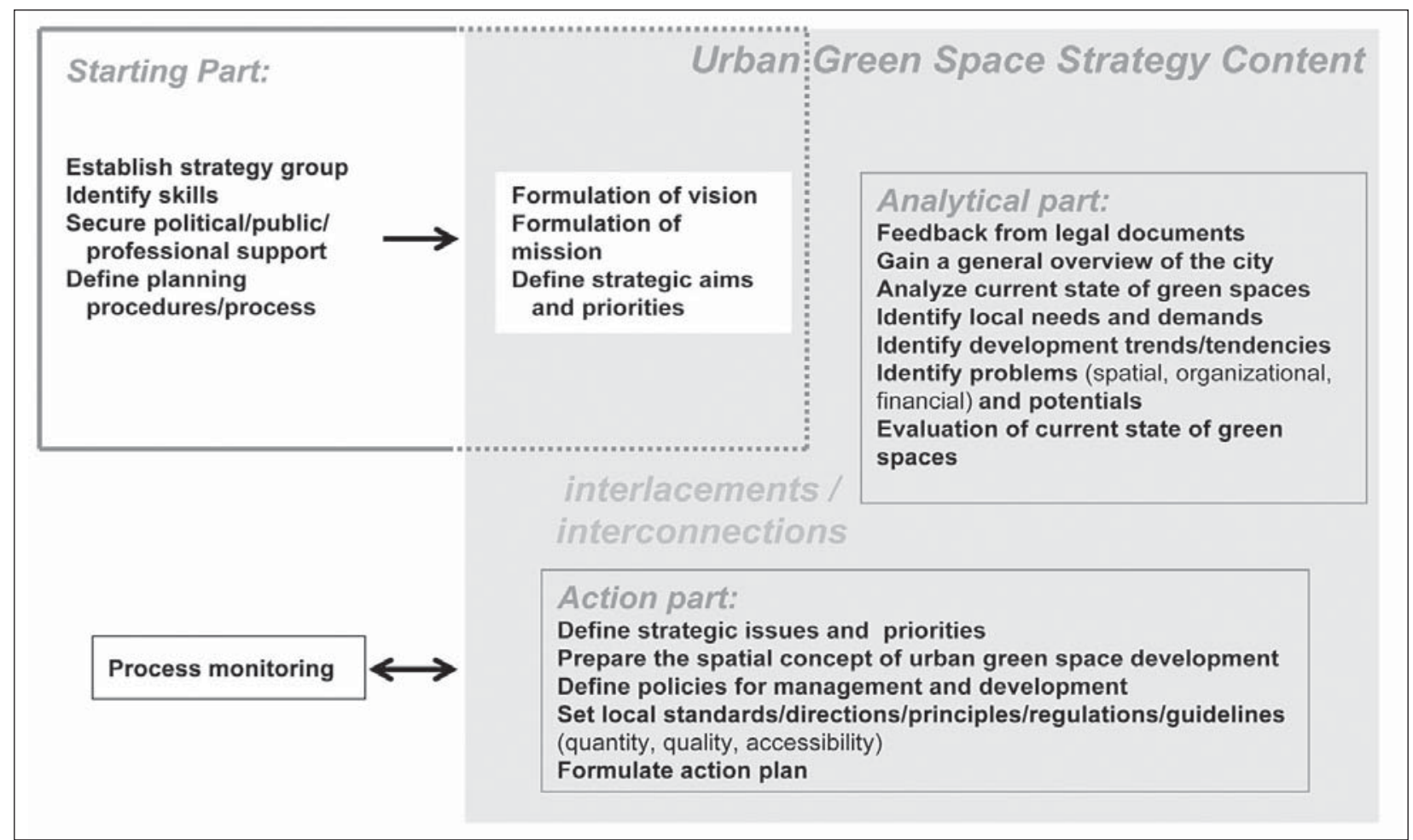

Figure 5: Elements of greenkeys green space strategy (source: UPIRS, 2007).

The GreenKeys Approach is not a blueprint that should be followed in strict adherence: it is more a model that offers a process to formulate an Urban Green Space Strategy. During the project process a basic framework has been formulated that is considered to be both necessary and helpful to use in all cases and situations whilst building up the green space strategy. It is developed from the experience of the GreenKeys partners, relevant literature (CABE Space Guide, UK PPG17) and other city experiences that have been presented during the project.

Put simply there will always be 3 parts to be developed and formulated, regardless of the generalities or detailed nature of the strategy itself:

- Starting part (preliminary activities);

- Analytical part (information gathering and evaluation);

- Action part (formulation of strategy).

During the project the monitoring system for the process of strategy building was developed and has been proved to be both useful and necessary.

The development of an Urban Green Space Strategy for most European cities is a novelty und therefore requires intensive and convincing pioneer work. Formulating the Urban Green Space Strategy is a comprehensive and quite demanding process that confronts the present situation of green spaces with the common values and needs of society, together with its economic prospects. To be really successful a good organisation is required, along with well founded and supportive cooperation between city departments, stakeholders and the public. It is very important to organise the work in an appropriate and meaningful way that suits the characteristics of the particular city.
The cross referenced evidence on developing a methodology for formulating an urban green space strategy suggests that urban green space development needs to be initiated by city administrations. This action has, in turn, to be supported by national and regional governments and by the European Union.

\section{Supporting tools for analysing and for increasing the performance of urban green spaces (systems)}

The traditional approach for the evaluation and development of green spaces is often characterised by a rigid splitting up into sectoral analysis. The different departments of a city's administration work on their own field of interest. Based on this type of sectoral approach, strategies for the development of urban green spaces often do not meet in consensus point. This process results typically in only quantitative targets (e.g. "create more green spaces") with little consideration being given to the needs of the local population, economic factors, wider planning targets or even the qualitative aspects of green spaces (e.g. biodiversity, accessibility). As a consequence, the emerging strategies for urban green spaces are not in harmony with the local circumstances. This effect is further compounded when other aspects of urban development (housing, infrastructure etc.) displace green space planning and development (URGE-Team, 2004).

To meet a holistic approach towards healthier built environment through better green spaces GreenKeys created a methodology for developing, formulating, and implementing an urban green space strategy for a whole city. To do 


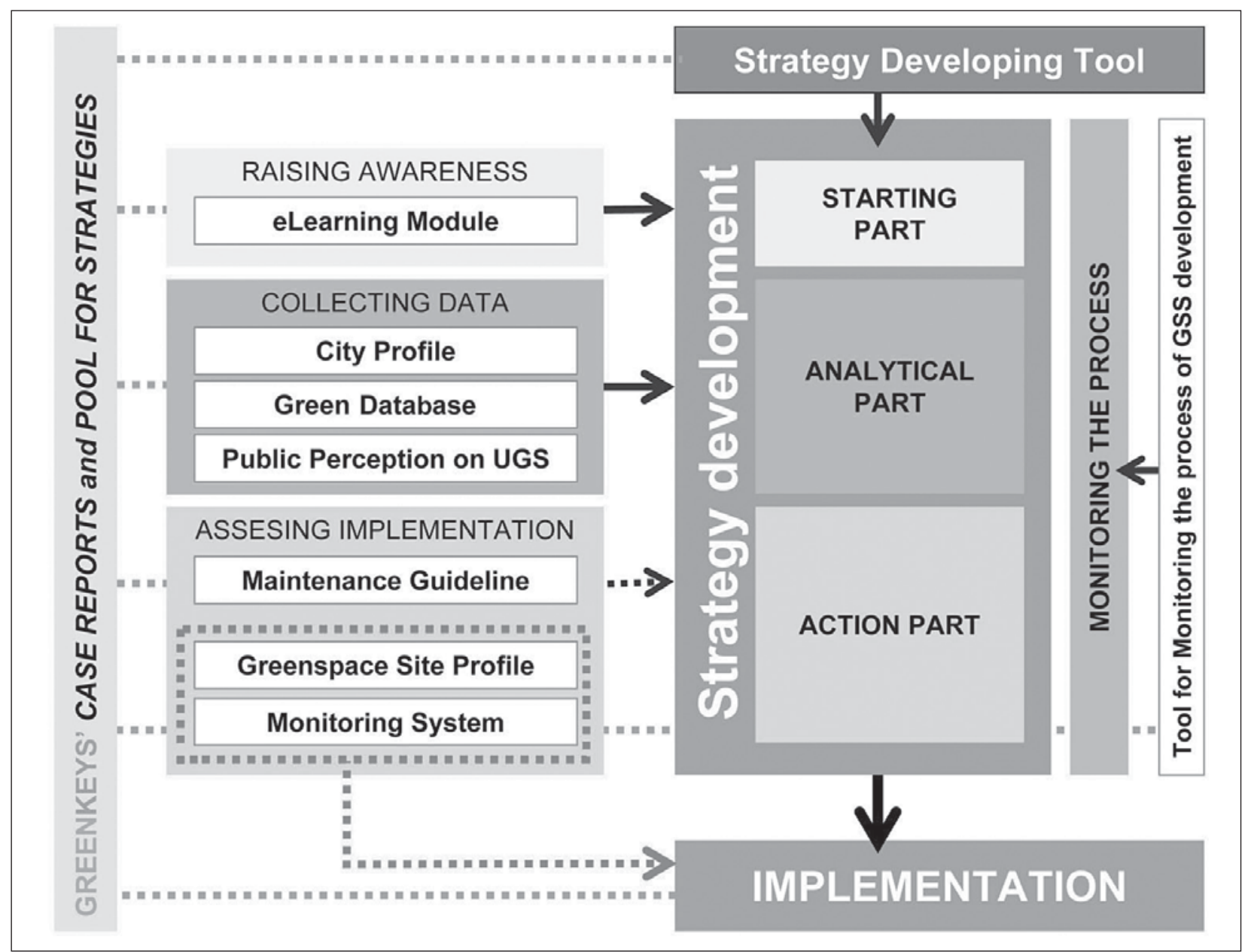

Figure 6: The tools and their integration: The use of GreenKeys Tools in the Urban Green Space Development and Management Process and how they support the formulation of an Urban Green Space Strategy.

this several tools have been developed to support the whole process. These supportive tools are set in the GreenKeys Toolbox - a coordinated set of instruments, techniques and recommendations that will aid the better understanding of urban green spaces and assist in the making of investment decisions for the future. The Tools developed by the GreenKeys Project, with their accompanying files, are available $n$ the manual or for downloading on the projects website at www.greenkeys-project.net.

Figure 6 provides an overview of the GreenKeys Tools and their application in the urban green space development and management process. The GreenKeys Toolbox offers the opportunity: to develop and to monitor the development of an Urban Green Space Strategy, to monitor changes in green space projects, to acquire information about peoples' perceptions of urban green spaces economic impact, and to manage data about city profiles and green characteristics. The tools permit the collection and organisation, in a comparable manner, of information about all projects and thus enable the further elaboration and analysis of the combined data.

The GreenKeys Tools are:

- The eLearning Module is a tool designed to assist and inform about processes and debates relating to the development of urban management strategies. It is primarily targeted at non expert professionals (politicians, decision makers, municipal administrators, etc.) who are seeking further information about the value and benefits that urban green spaces can bring to the development of the urban environment. The module is conceived as an interactive HTML formatted file, running on the main operating systems (such as both Windows ${ }^{\oplus}$, and $\mathrm{Mac}^{\oplus}$ ) with the most common browser software, and can be used during workshops and training courses.

- The City Profile is a questionnaire designed for the compilation of information about a city's general structure and organisation in relation to its green space provision. The questionnaire aims to record the characteristics of the physical, constitutional, institutional, and operational environments of a city. The knowledge that is gained about these characteristics is of considerable use in acquiring an understanding of the local system. It is particularly useful to learn about how the system is structured and the manner in which it functions in the domains of spatial planning and urban governance. The City Profile, therefore, once compiled, enables the user to carry out a self assessment as a basis for a city's Urban Green Space Strategy and for any successful implementation of related green projects. The City Profile, together with the Green Space Site Profile provides data for the Green Database. 


\section{GRTE'NKEYS}

URBAN GREEN AS A KEY FOR SUSTAINABLE CITIES

\begin{tabular}{|l|l|l|l|}
\hline City & Date & \\
\hline Institution & \multicolumn{3}{|l|}{} \\
\hline
\end{tabular}

\section{Area, land use and population \\ I.I. Please indicate the area for development of the green strategy \\ Reference year for the above data: \\ I.2. Please specify the kind of boundary you use to determine this area (e.g. city area, municipality area, administrative border, urban region area, etc.)}

> A map with the borders mentioned in I.I could be very useful

I.3. Land use (built up area, except urban green and open spaces)

Area types (You can use your own land use categories instead of the proposed (e.g. according to a land use plan such as the "Flächennutzungsplan" or urban biotope mapping results.)

Residential areas

Industrial areas

Commercial areas

Mixed use areas

Infrastructure (Roads and other transport routes)

Land use (built up area) (total)

Other, please specify

Reference year for the data above

\begin{tabular}{|c|c|c|}
\hline Total area & Proportion & $\begin{array}{l}\text { Proportion of } \\
\text { green + open } \\
\text { spaces inside the } \\
\text { area }\end{array}$ \\
\hline $\mathrm{km}^{2}$ & $\%$ & $\%$ \\
\hline $\mathrm{km}^{2}$ & $\%$ & $\%$ \\
\hline $\mathrm{km}^{2}$ & $\%$ & $\%$ \\
\hline $\mathrm{km}^{2}$ & $\%$ & $\%$ \\
\hline $\mathrm{km}^{2}$ & $\%$ & $\%$ \\
\hline $\mathrm{km}^{2}$ & $\%$ & $\%$ \\
\hline $\mathrm{km}^{2}$ & $\%$ & $\%$ \\
\hline $\mathrm{km}^{2}$ & $\%$ & \\
\hline $\mathrm{km}^{2}$ & $\%$ & \\
\hline \multicolumn{2}{|l}{} & \\
\hline
\end{tabular}

uses available? Please describe briefly the contents of these maps.

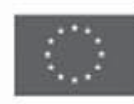

GreenKeys is part-financed by the European Union Community

Initiative INTERREG III B

www.greenkeys-project.net

Figure 7: The GreenKeys city Profile examples of questions. 
- The Strategy Developing Tool is designed to help city local government and administrative bodies to become involved with, organise, develop and implement an Urban Green Space Strategy. It supports and steers the process of planning and managing the development of such a strategy and the goal of creating a vision for a sustainable city future. The 'Strategy Development Tool' includes: the 'Strategy Development Guide', that provides a working framework (the procedure followed, however, must reflect the local conditions and requirements); and the accompanying 'Content Table', for a quick overview.

- The Strategy Developing Monitoring Table as a tool to assist the user in monitoring the process of the Urban Green Space Strategy development. The main purpose of the tool is to check and monitor the process of building the Urban Green Space Strategy, together with its development in terms of time and content. By filling in the table a quick overview is obtained of the process situation which can be presented to politicians and the public with good prospects of achieving a robust, rounded and lasting green space strategy.

- The Maintenance Guideline provides guidance and support to enable European cities to formulate and implement their own strategies, methods and tools for the maintenance of their urban green spaces. In the Maintenance Guideline are highlighted a number of the key points, which impact on best practice in urban green space maintenance. In the light of that remarks a number of questions that municipalities need to think over in formulating their green space maintenance strategies are posed out. These are framed around the six key headings: vision, monitoring, organisation, skills, funding and participation.

- The Tool for Public Perceptions and Attitudes towards Urban Green Spaces can be used by a city authority to estimate citizens' opinions, positions thoughts and feelings about the existing and prospective green space in their city also in relation to the economic aspects of urban green. The questionnaire explores attitudes towards alternative uses of urban green space and addresses the issues surrounding the financing of its provision, maintenance and expansion. Being aware of people's views is important for a city as they can provide a basis for the formulation or redirection of relevant policies concerning urban green.

- The Green Space Site Profile is a questionnaire designed to help a city to organise, monitor and evaluate the development of new green space and the improvement of existing green space. The tool aims to describe the characteristics of each green project and its implementation process on the basis of a set of questions. It facilitates the evaluation of existing conditions (characteristics, strengths, needs, problems, etc.) and the implementation process, along with the assessment of prospective outcomes.

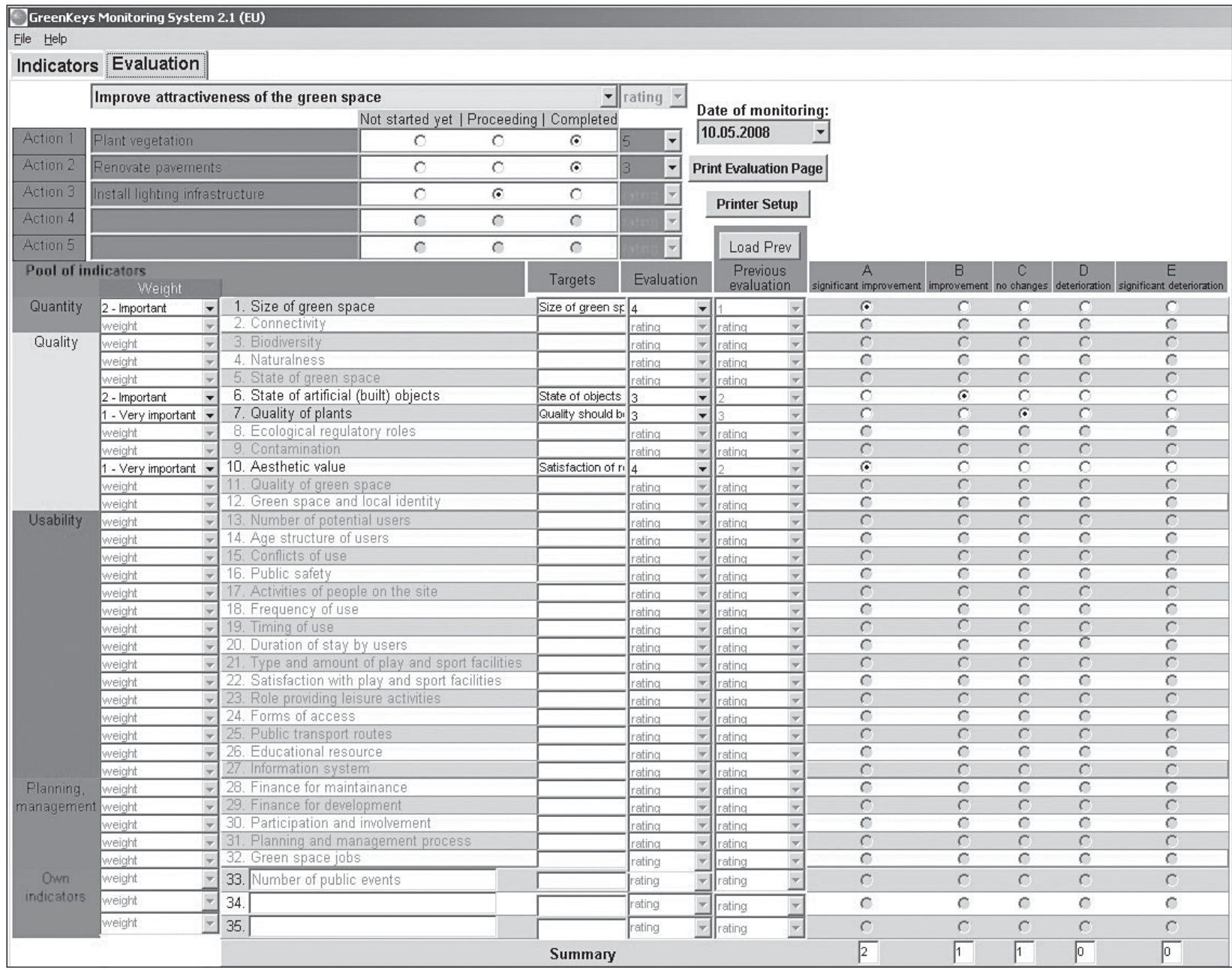

Figure 8: The evaluation sheet of the GreenKeys Monitoring System showing an example. 
- The Green Database is Microsoft (MS) Access Database template which incorporates questions raised in the City Profile and the Green Space Site Profile. The Green Database enables the systematic and effective elaboration of data bundles in such a way as to facilitate a quick search, and production of the related information. The database offers the prospect of creating related databases in the form of tables, executing macro-commands, posing questions and producing printed reports. It can provide combined information about different projects, as well as about a single project in different time periods.

- The GreenKeys Monitoring System is a tool geared to make changes visible and control the implementation of new or the improvement of existing urban green spaces. With 32 clear and measurable numeric indicators it is suitable and applicable for an easy and effective monitoring of implementation projects. It helps too, to control self set targets during the whole implementation process of a green space project. The progress made can be displayed and any discrepancies detected early.

The Tools City Profile, Maintenance Guideline, Tool for Public Perceptions and Attitudes towards Urban Green Spaces and Green Space Site Profile are available in two versions, (1) in PDF/Adobe Acrobat format, where you only can fill in your data and (2) in MS Word format, which you can change for your own needs, if you want.

The Tool Strategy Developing Monitoring Table is available in MS Word in two versions: (1) as a form, where you only can fill in your data and (2) in a file format, which you can adapt to your own needs.

\section{Supporting the learning process in the practice - implementation of pilot projects}

Following the project's objective 2 all partner cities were enabled to implement a pilot project ${ }^{[2]}$ which directly benefited the population and the environment around the area. Together with local stakeholders, the cities created new or improved existing green areas with especial attention given to social, ecological and economic requirements. The idea was to break new ground and come up with new ways to achieve green space development.

Examples for pilot projects are:

- the revaluation of residential areas by improving green spaces (Xanthi, Budapest),

- the creation of outdoor possibilities for recreation and sports on green areas (Volos, Giulianova, Sanok),

- the rehabilitation of derelict land into green spaces (Leipzig, Nova Gorica),

- the revision of an historic park (Dresden, Kotel) and a botanical garden (Bydgoszcz) as well as the improvement of open spaces with endemic vegetation (Halandri).

These pilot projects were implemented with combined objectives:

- provide recreation, sports, and entertainment opportunities,
- increase accessibility and usability,

- combine with educational and/or cultural activities mostly in the sectors of archaeology, history, and the environment,

- increase security and safety in the use of urban green spaces,

- improve the overall city image,

- provide services for user groups with special needs - e.g. children,

- develop socio-political dimensions: increase and enrich public participation, increase public awareness and strengthen the social fabric of the surrounding area or of the city as a whole,

- increase biodiversity.

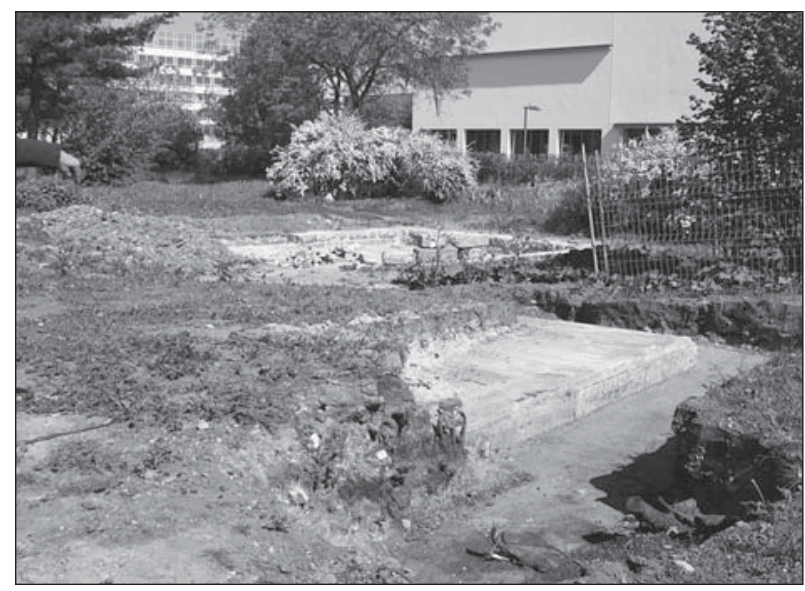

Figure 9: Excavation works in Dresden revealed some interesting aspects of the former park design (source: Dresden, 2006).

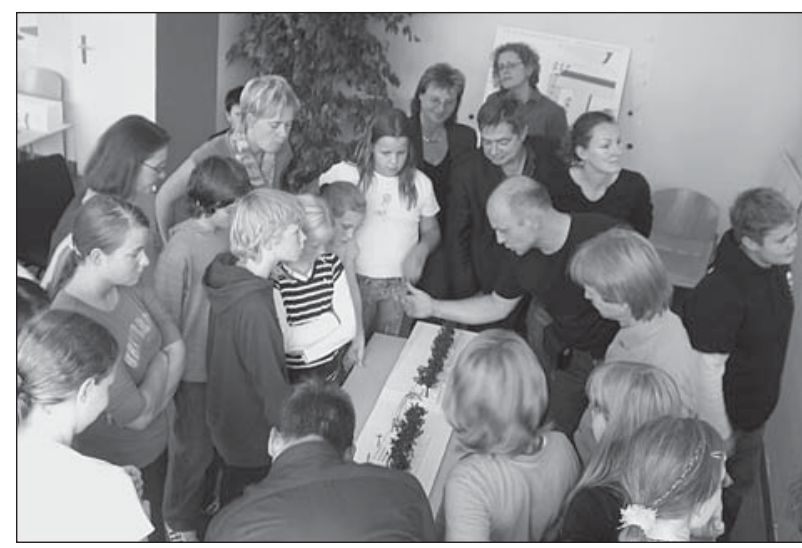

Figure 10: Brainstorming session with students to discover design ideas for the teenagers' venue in the Bürgerpark in Leipzig (source: Grünflächenamt Leipzig, 2007).

Green space and public participation have to be closely related since they each constitute major elements of sustainable development. Public participation is the issue that has been addressed extensively in all pilot projects.

Public participation is a complex issue. In GreenKeys we fixed on the topics:

- reasons and scope of public participation;

- identification of the participants and among those the drivers; 

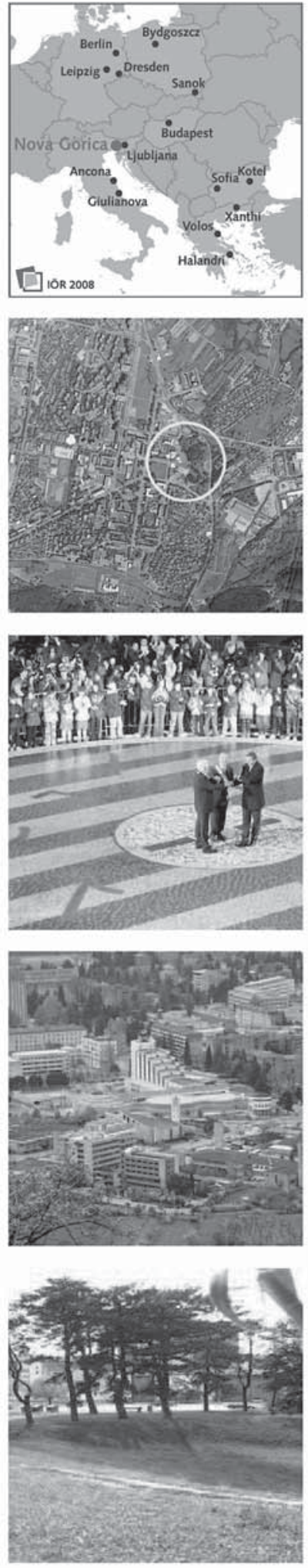

GreenKeys is part-financed by the European Union Community Initiative INTERREG III B www.greenkeys_project.net

\begin{tabular}{|l|l|l|l|}
\hline Municipality area & $13 \mathrm{~km}^{2}$ & Population & $20.000(2002)$ \\
\hline GDP per inhabitant & $\begin{array}{l}15170 \quad \in / \text { year } \quad \text { (for } \\
\text { Slovenia 2006) }\end{array}$ & Trend & decreasing \\
\hline Area of green spaces & all open spaces: $5,43 \mathrm{~km}^{2}$; urban green spaces: $0,43 \mathrm{~km}^{2}$ \\
\hline Area of green spaces per inhabitant & $271,5 \mathrm{~m}^{2} /$ inh. (all open spaces); $21,5 \mathrm{~m}^{2} /$ inh. (urban green spaces) \\
\hline
\end{tabular}

\section{Nova Gorica and its green structure}

Nova Gorica is situated within a flat valley, on the edge of Goriška plain and is surrounded by low hills to the north, east and south. The municipality lies close to the border between Slovenia and Italy. hence Nova Gorica has close ties with the Italian city of Goricia. The maritime climate, with hot summers and mild winters, allows the use of urban green spaces throughout the year.

The city is surrounded by wide green areas which in places penetrate the urban tissue. Within the city there are many smaller green areas: some are already developed as parks whilst others remain untendered and unkempt. Panovec urban forest plays a very important role in the city's urban structure as a recreational and leisure facility.

Nova Gorica was planned with a strong influence from the modernism movement as a 'city in green'. This concept is noticeable in the city structure which is distinguished by wide, parallel and perpendicular streets together with intervening built structures and green spaces. These are not, however, equally distributed within the urban fabric and some residential areas, especially those that are newly built, suffer from a deficiency of urban green spaces.

There is an accelerating trend to give up agricultural land use within the urban area. This results in deterioration into unused accommodation land and building plots for development of new residential areas.As the expansion of the city is limited there are pressures to preserve those spaces which have not yet been built upon.

There are some studies and projects (ecological stability, protection of biotopes and species, vulnerability of recreation areas) that support the development of urban green spaces. To achieve this, minor problems remain such as insufficient finance, political instability, bureaucracy, maintenance, an ineffective green planning system, lack of cooperation within the administration and growing pressures to build on the areas.

Another problem the city is confronted with relates to questions of land ownership following independence. The issue of ownership of most of the major green spaces within the high density residential areas is still proceeding before the competent court. The tendency to privatize public space through this judicial process can lead to a limiting and shrinking of public green spaces. The challenge of the municipality is to prevent the spread of this process and to secure ownership of urban green spaces.

\section{Urban green space strategy}

The challenges and approach to building an urban green space strategy

There is no legally binding spatial legislation for green space strategy development in Slovenia, so the municipality chose not to accept GSS as an independent document

A working version of such a document has been created by the city administration while working on the Green Strategy issue. As a consequence of this work we now have a preliminary draft of the Green Space Strategy which provides:

- the vision:

- goals;

- guidelines for modifying appropriate spatial documents and administrative acts (such as the master plan, the town's urban plan, its strategic and implementing section, ordinances on maintenance of public areas, ordinance on the city appearance);

- guidelines on green space typology (type, inventory, quality, deficiencies, policy).

The Strategy foresees:

- the establishment of required registers, such as the green areas register, and the planted species register

- how and when set goals are to be reached

- the basic coordination amongst task performers; and

- the completion of the basic goal of the draft - presenting the Green Space Strategy to the City Council to gain its approval.

At the present time there is a low level of political and public support for preparing the green space strategy. The first and most important challenge is to raise public awareness and political interest about importance and benefits of a green space strategy for the city.A public information publication about the possibilities and challenges of urban green in the city has been prepared as a first step towards the green space strategy. Once the publication has been presented to the municipal administration to get legal support the development of the strategy will follow.

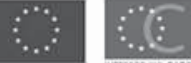

Figure 11: Shows a case report example - Nova Gorica. The case reports are available under the topic City Folder in the CD-ROM Tools. 
- the timing/phasing of the participation (when to involve whom).

The participation process also contains political values which often determine its characteristics. The ideology/ political values define the scope of participation, which selects the participation strategy, which reinforces ideology/ political values.

The following tools were implemented to support the planning and implementation process of the pilot projects: the City Profile, the Description of the Pilot Project, the Tool for Public Perception and Attitudes, a Monitoring System, and a Database containing information about each of the pilot projects.

These tools permitted the collection and organisation of information about all the projects in a similar way. The combined data could then be the subject of further elaboration. The gathering in and analysing of the information from the pilot projects provided some essential knowledge to put the Urban Green Strategies onto a satisfactory empirical basis. In addition to the implementation of the pilot projects, GreenKeys has achieved the added value of providing valuable tools for general 'Green Space' and 'Green Strategy' use.

Even with the provision of incentives (extra budget position and knowledge transfer support) the implementation of pilot projects did not always occur without problems and obstacles. The most frequent problems, ranked according to occurrence, had been:

- limited or no public participation in some or in all phases of the project,

- no cooperation between the levels and departments of local administration with responsibility and/or involvement in the project,

- bad planning, poor management, specially aggravated by the poor cooperation between the levels and departments,

- not enough human resources and additional unplanned tasks,

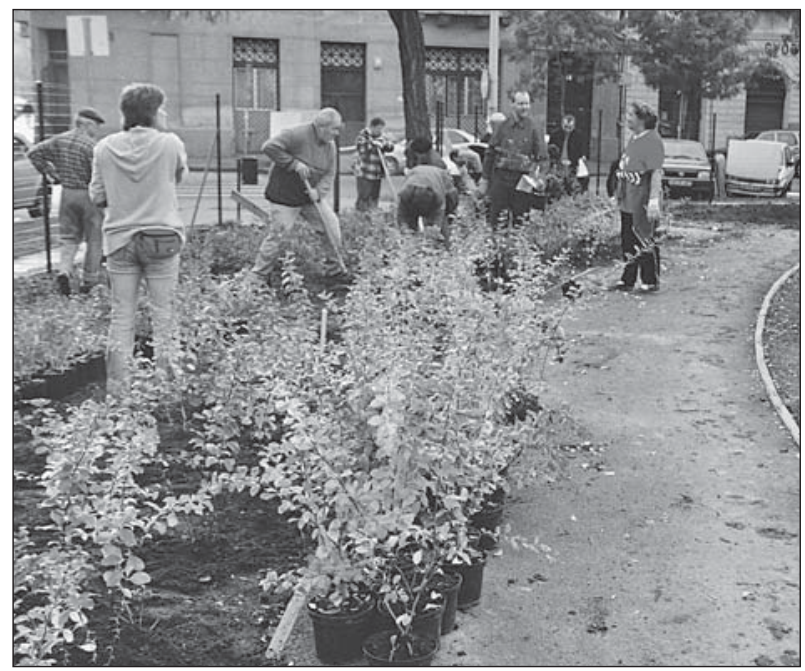

Figure 12: Residents at the planting action in Budapest.
- bureaucratic and/or legal complications and resulting delays,

- no political support,

- incidents of vandalism,

- required change(s) of/in the project and resulting delays,

- shortage of funding - each partner city had an extra budget allocated for the implementation of their pilot project. This budget needed, however, a counterpart funding called as co-financing. Providing the co-financing became in some cities problematic.

\section{A brief aside on public involvement}

The evaluation of participation is a complex issue. 'Objective' evaluation cannot be achieved as there are various categories of participants, each with different interests and objectives for participating. In general, participation should be evaluated by each participating group/agent separately and according to the initial objectives of this group. If objectives are achieved as a result of participation, the evaluation will be positive.

Taking two of the above mentioned problems more detailed - limited or no public participation and the incidents of vandalism, we can exemplary present solutions developed by the City of Leipzig (Germany) to tackle them: Both problems are very intrinsically linked - as long as a green space does not enjoy its social role, the less people use it, the less this people is interested in its development, the more acts of vandalisms can be identified.

In some GreenKeys partner cities the gathering of public support was a new approach and experience. In some countries public participation has not been commonly or widely used in the past. Despite the fact that there is no tradition of people being involved, the GreenKeys partner cities organised several public events in order to inform inhabitants about the work being undertaken.

Leipzig puts a lot of effort into public participation and involvement because the city is faced with very problematic social conditions in the locality of the pilot project. Young people had been unable to find any leisure facilities and social conflicts (youth gangs) have arisen. The public involvement started at the initial stage of the project with a local workshop, design competition and public discussions. This was followed by local workshops with citizens living in the neighbourhood and young people were interviewed. This led to a high level of acceptance of the project by the residents and increased the levels of interest of political parties and the mayor himself. The venue has been planned, supported by a public design workshop for a boundary graffiti wall. The 50 best results were presented in the Mayor's hall. In autumn 2005 the initial action took place: the wall was created with graffiti, in close collaboration with the adjoining school, the local citizens' initiative and a graffiti artist. The public information process has continued and two more graffiti walls have been successfully undertaken, in turn improving public commitment. The planning and construction process on adjoining green spaces has continued. Presentations and local consultations have safeguarded the involvement of local people and different stakeholders for the long-term maintenance concept at the site. Particularly the public signing of 
a 'contract' for a long-term maintenance of the venue with young people is expected to be long lasting and with this be a step in avoiding vandalism.

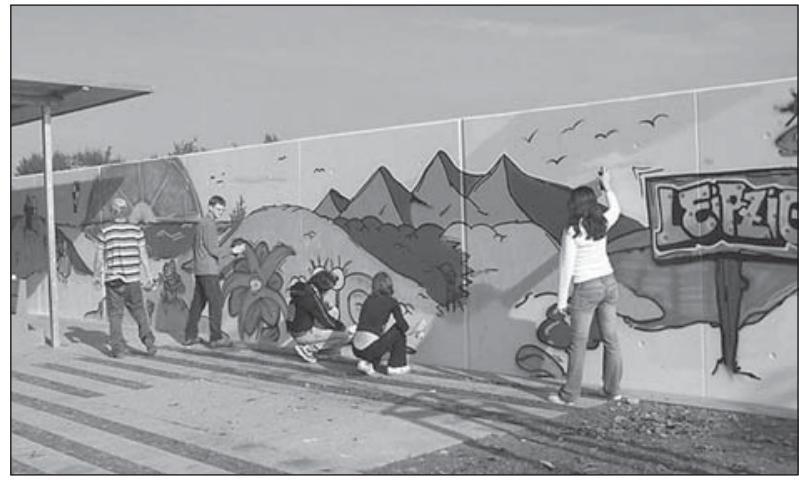

Figure 13: Leipzig worked together with teenagers and developed with their involvement a meeting teenagers' venue in the Bürgerpark. Here the wall was painted with graffiti made by the teenagers (source: City of Leipzig - Parks and Recreation Office, 2005).

An important aspect of public involvement concerns the precise identification and the analysis of stakeholders and their interests. There is a need to know who shares expertise in and concern for green spaces issues. In GreenKeys the involvement of different stakeholders in the planning process has led to a high acceptance of the pilot project and in the case of Leipzig a commitment for long-term maintenance. The experiences show that stakeholders must be given a clear shared vision with achievable objectives and performance indicators to ensure success.

\section{The GreenKeys manual and beyond the project}

We believe that with all GreenKeys results, particularly 1) the improvements made in green spaces in 12 different cities with the implementation of the pilot projects, (2) the kicked off process of formulation and consultation of the Urban Green Space Strategy and (3) the knowledge and experience exchanged and transferred, help has been provided and awareness and interest raised to enable city administrations to address and deal with their green space in a more comprehensive and intensive way.

The proposed GreenKeys Methodology and Tools are recommended as a means of identifying the drivers and establishing a system and working approach for developing, adopting and monitoring the implementation of comprehensive urban green space strategies. Through this documentation GreenKeys supports the creation of a shared vision to give strong, sustainable identities to the futures of our cities.

The project results are compiled in the manual GreenKeys @ Your City - A Guide for Urban Green Quality, which is designed in the hope that it will prove to be an inspiration in the spirit of GreenKeys: Improving green space is a commitment for an investment into the future. It provides ideas about ways to solve problems rather than recipes or dictates to be strictly followed. The target groups for GreenKeys @ Your City are practitioners searching for solutions for solving specific problems in their cities and the scientific community: obtaining inputs for scientific discussions and ideas for necessary further research.

Dr. Carlos Smaniotto Costa

Leibniz Institute of Ecological and Regional Development (IOER) Dresden

E-mail: c.smaniotto-costa@ioer.de

\section{Dr. Juliane Mathey}

Leibniz Institute of Ecological and Regional Development (IOER), Dresden

E-mail: j.mathey@ioer.de

Mag. Ina Šuklje Erjavec, Landscape Architect

Urban Planning Institute of the Republic of Slovenia, Ljubljana

E-mail: ina.suklje-erjavec@uirs.si

\section{Notes}

[1] The list of benefits and functions can be very extensive. For further information consult the GreenKeys Manual 'GreenKeys @ Your City - A Guide for Urban Green Quality'. There the most significant benefits and further literature hints are listed.

[2] Bulgarian cities Kotel and Sofia, along with the Union of Parks and Landscape Experts, did not have any financial support to participate in the GreenKeys project. Bulgaria was not a member of the European Union at the time the project was proposed and commenced: consequently no direct European funding could be secured. A later additional proposal, prepared by the Bulgarian partners, was unsuccessful in securing funding and was rejected. The lack of financial support resulted in a significant challenge for the whole project team which could be only partially eased through the personal engagement and commitment of the partners. The implementation of a pilot project could not, however, be achieved, nor could the development of a green space strategy be realised. The participation of Bulgarian partners in the GreenKeys Project could be undertaken only on the basis of participation in the workshops and through networking and knowledge transfer. This was achieved through additional financial support being made available by the German Federal Ministry of Transport, Building and Urban Affairs.

\section{References}

Barber, A. (2005) Green Future - A Study of the Management of Multifunctional Urban Green Spaces in England. Reading, Green Space Forum Ltd. de Vries, S., idr. (2001) Benefits of Green Space for Physical Activity in Adults. Euro Leisure Congress. Netherlands.

CABE Space (2004) Green Space Strategies - making the most of your parks and green spaces. London, UK: Cabe Space. Dostopno na: http://www. cabespace.org.uk/data/pdfs/greenspacestrategies.pdf)

Greenkeys-Team (2006) Guideline for the General Procedure of Developing and Implementing an Urban Green Space Strategy. Availabe at: http:// www.greenkeys-project.net/media/files.

GreenKeys-Team (2008) GreenKeys @ Your City - A Guide for Urban Green Quality. Dresden, IOER.

ODPM/Communities and Local Government 'Planning Policy Guidance Note 17: Open Space, Sport and Recreation'. London. Availabe at: http:// www.odpm.gov.uk

URGE-Team (2004) Making Greener Cities - A Practical Guide. UFZ-Bericht, 8(37) (Stadtökologische Forschungen). 